\title{
Argos en el infierno de LOS PERROS: una mirada cínica a la identidad desde Fernando Vallejo
}

\begin{abstract}
Resumen
El artículo analiza el tema de las identidades latinoamericanas en Peroratas (2013), del escritor colombiano Fernando Vallejo. Desde una perspectiva deconstructiva, la identidad se piensa como imposible en la medida en que se opone a la diferencia. A su vez, la diferencia como elemento irreductible de los sujetos individuales y colectivos se articula con las implicaciones teóricas de la metáfora de la mirada para establecer la metáfora misma como identidad.
\end{abstract}

Palabras claves: Fernando Vallejo, identidades, mirada, metáfora, autoficción.

Mauricio

Chaves.

Filólogo, estudiante de la Maestría en Literatura Latinoamericana en la Universdiad

de Costa Rica. rmao.cf@gmail.com

\begin{abstract}
The article analyzes the portrayal of Latin American identities in Peroratas (2013), by the Colombian writer Fernando Vallejo. From a deconstructive approach, identity is deemed impossible to the extent in which it opposes difference. At the same time, difference, irreducible in individual and collective subjects, is articulated through the theoretical implications of the metaphor of the gaze, in order to establish the metaphor itself as identity.
\end{abstract}

Keywords: Fernando Vallejo, identities, gaze, metaphor, autofiction.

\section{"Si fuere necedad, perdonadla..."}

Yo querría, como Sor Juana, pedir perdón por estos borrones míos. No sé escribir y uno no debería meterse a hacer lo que no sabe. Pero no soy una monja ni sé un carajo de retórica, de manera que me voy a conformar con pedir paciencia. Aunque pensándolo bien, decía Derrida que el perdón es del orden de lo imposible, que sólo se puede dar ahí donde es imposible perdonar. Siendo así, y a la vista de que esto ya va resultando imperdonable, pido perdón a todo aquel que lo leyere.

\section{An Earthling named Delmore Skag}

Y si no soy una monja, ¿quién soy? Pues bien, en primer lugar soy un terrícola: an Earthling, como si me nombrara un extraterrestre con esa ironía de Vonnegut 
que esconde el hecho de ser extraños en nuestro propio mundo. Del artículo indefinido se deduce que soy un hombre y a eso le podemos agregar algunos bato de lucidez barthiana que $h$ guardado para mí como un principio ético:

Tolera mal toda imagen de sí mismo, sufre si es nombrado. Considera que la perfección de una relación humana depende de esa vacancia de la imagen: abolir entre los dos, entre el uno y el otro, los adjetivos; una relación que se adjetiva está del lado de la imagen, del lado de la dominación y de la muerte (Barthes, 2004, p. 59).

En La cámara lúcida (2009), él mismo puso en evidencia este vínculo inquebrantable que une la imagen fotográfica y la muerte. El eslabón que los une, ese ojo de hierro, es la mirada castradora que atraviesa el objetivo para determinar aquello que deberá hundirse en el ámbito de lo irrecuperable. Con un disparo, en un instante de luz, llegan juntas la ceguera y la muerte. El esto ha sido de la foto queda como una prueba de que el ser y la mue que se oculta bajo la luz. tanto apunta a inmovilizar un objeto que se le escapa, es asesina, sicaria:

¡Tas! Un solo tiro, seco, ineluctable, rotundo, que mandó a la gonorrea esa con su ruido a la profundidad de los infiernos. ¡Cuántas veces no he pasado la escena por mi cabeza en ralentí! Veo sus ojos verdes viéndolo. Verdes turbios. Embriagados en lo irrepetible del instante. iTas! Un solo tiro, sin comentarios. Alexis guardó el revólver, dio media vuelta y siguió caminando como si nada. ¿Por qué no le disparó por detrás? ¿Por no matar a traición? No hombre, por matar viendo los ojos (Vallejo, 2012, p. 26).

Así advertidos sobre los peligros de la imagen, la adjetivación y la definición en general, volvamos al que no era una monja. Podemos decir, con temor a equivocarnos, que además de terricola "soy" latinoamericano, costarricense, herediano, maxista, capitalista, de clase media, sin clase, ateo, aburrido, desilusionado, enamorá escribir carour Mientras, por un lado, el probioma de adjetivar consiste en que se revela semejan te a un proceso de disección, el inconveniente de la identidad es, más bien, el de la taxidermia La identidad tiene la forma de una tautología: define una cosa a partir de sí misma la fija en su apariencia más inmediata. Es matemática de escuela: $x$ es igual a $x y x$ es una constante, va a ser ella misma ahí donde está y en donde sea que se la ponga, a la par de otro número o metida en una ráz cúbica, por los siglos de los siglos amén. Pero este lugar no es precisamente el Topos Uranus ni paraíso perdido. Aquí las cosas cambian, las personas cambian, todo es relativo. Lo supo mi bisabuelo que no fue a lo escuela, pero le tocó a Einstein demostrarlo y al final lo terminó entendiendo hasta la jirafa de Monterroso.

Y ya que empezamos a hablar de animales, ipor qué no seguimos con Fernando Vallejo? El domingo pasado me entró una desesperación tremenda por comprar uno de sus últimos libros, Peroratas (2013), y desafiando el peligro rampante de una espesa niebla y semáforos apagados me fui manejando hast eso que Luis Chaves llama el Estado Separatista de Escazú para conseguirlo. Lo compré, y una vez que me hallé con él, encontré que todos sus textos estaban en Internet. iQué raro, en medio de tanta niebla no vi la nube! Sin embargo, me sentía contento. Llegué a mi casa, me lo senté en la palma de la mano como un bebé de regazos y empecé a carcajearme con él y a contarles sus gracias a mis familiares. El libro reúne conferencias, ensayos, artículos, ponencias y otros textos ya publicados y leídos entre 1996 y 2012. En él Vallejo insiste sobre sus temas de siempre: la inexistencia de Dios y de Cristo, los crimenes de la Iglesia y de los políticos, el crimen de fraterna con los animales.

A quien le daba lo mismo "mismo y mesmo"

La identidad (o las identidades, como dicen ahora, después de verle la otra cabeza al monstruo), no es asunto que interese particularmente al colombiano. Para muestra, desprecio que siente por Hamlet frente al Quijote. Escuchemos:

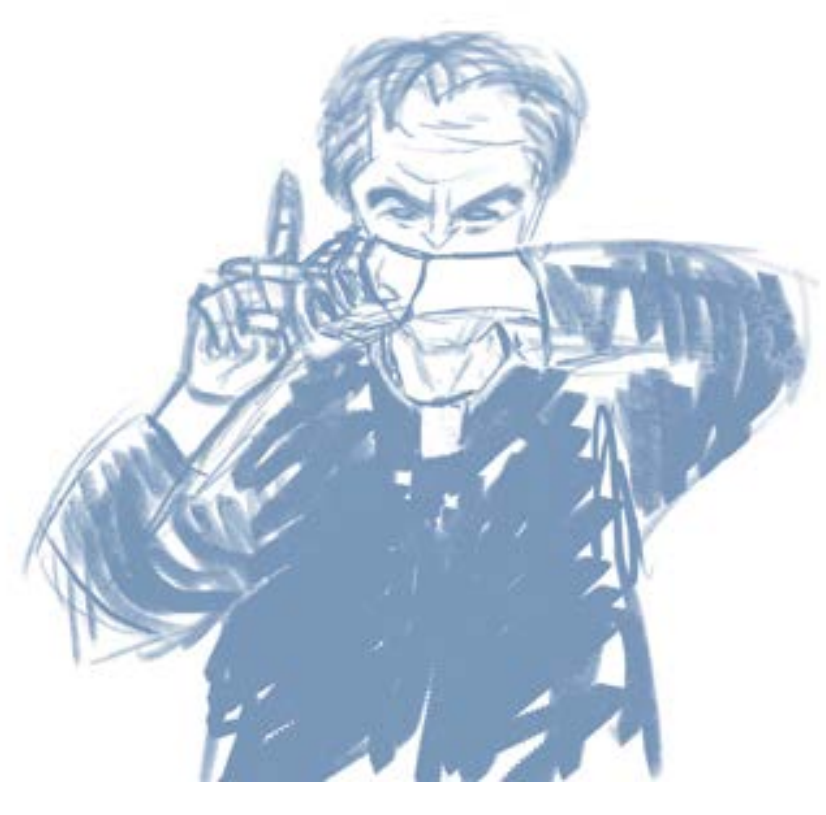

Y oigan esta otra maravilla: "Eso me semeja

-respondió el cabrero a lo que se lee en los

libros de caballeros andantes, que hacían todo eso que de este hombre vuestra merced dice, puesto que para mí tengo o que vuestra merced se burla o que este gentilhombre debe de tener vacíos los aposentos de la cabeza". Entonces el gentilhombre, que es nadie más y nadie menos que don Quijote, le contesta: "Sois un grandísimo bellaco, y vos sois el vacío y el menguado, que yo estoy más "leno que jamás lo estuvo la muy hideputa puta que os parió". iEso es hablar, eso A A mi Hamlecitos, y a tales horas? (Vallejo, 2013, pp. 92-93).

¿El problema de las identidades? Esas son vagabunderías de los académicos. ¿ldiay? ¿Entonces? ¿Cómo es que se escribe sobre un tema en un autor sin que ¿diay? ¿Entonces? ¿Como es que se Escribe sobre un tema en un autor sin que impertinente, una perorata? ¿Por qué no? Ya nos arreglaremos. Por vo pronto digamos que se requiere una aproximación oblicua, especular, sesgada, mirona. No se trata de lo que Vallejo diga o deje de decir, sino de cómo afinamos el ojo para verlo. El ojo que señaló como la parte del cuerpo que no envejece. el que mata y muere. La ventana del alma.

\section{" ¡Ay, Clarita, por Dios, qué locura, se te corrió la teja!"}

Otros sí se han ocupado de la tarea voyerista de hacerse ver mirando: José Cecilio del Valle, Martí, Rodó, Reyes, Vasconcelos, Henríquez Ureña, Paz, Fernández Retamar, García Márquez, Carpentier, Rojas, Fuentes y un sinnúmero de otros. A todos los afanó la necesidad de encontrar el elemento que armara de una vez por todas el rompecabezas de lo latinoamericano. La cosa era encontrar el nudo, no importaba dónde. Esto los llevó a explorar muchas dimensiones del fenómeno: la política, la cultural, la étnica, incluso la espiritual, lo que sea que quiera decir eso.
Sin titulo. 
Cada uno aportó lo que pudo y dejó su huella: José Cecilio y Martí nos legaron la nostalgia de lo que pudo haber sido América Latina de no haberse ido separando en unas cuantas fincas; Rodó imaginó un lugar de ideales basados en la Grecia clásica y el cristianismo; Fernández, por el contrario, una tierra materialista y bárbara que se opusiera sin reservas al dominio externo; Vasconcelo creyó que el destino latinoamericano era mezclarse hasta producir una raza nueva fundada en el amor; por último, Reyes nos dejó el retrato de un Anáhua majestuoso que parece más el sueño de un viajero errante que lo visitara. Así, fisgoneando por la cerradura de sus cerebros fueron viendo lo suyo, escribiendo sus visiones en papeles que iban enrollando y tirando por el ojo del palastro hasta que alguien los notara del otro lado y los reprendiera por su perversión. Hasta ahora, ningún sabio ha bajado del cielo a decirnos a ciencia cierta cua de todos tuvo la idea más absurda. Para empezar con José Cecilio y Marti, a quie nes estimo sobremanera, dejemos claro que América siempre estuvo fragmentada, desde antes de la conquista, que terminó de quebrarla en mil pedazos. La division es una gran manta del ser humano: todo qu mundo se las quiere dar de autónomo. Sobre todo los ricos, que han depend do siempre de sus esclavos los pobres. Aunque eso es lo de ménos porque, za quín se le ocurre juntar a los griegos con Cristo? Como anotó Blerce en su zagnifico satanario, los griegos se inventaron a Cristo para azotarse con ella Veinticinco años después de Rodó, inventaron a Cristo para azotarse con ella. Veinticinco años después de Rodó, Y Y cuando se pensaba que no habia más allá, legaron los teólogos de la liberación a juntar a Cristo con Marx. Es que en estas cosas la humanidad si progresa...

Al lector que, habiendome perdona porque no que, habiendome tener los cristiando a sus er de teneresentación. Como yo no sé escribir desde el principio me puse a jugar a yue re Vallejo y, de forma, imaginando qué dirí él y que no, me ayugar a que era Vallejo $y$, de esa forma, imaginando qué dira él y que no, me ayude a lanzar cadencia del color mi dialecto costarricense. Es tanto así que, aunque estoy seguro de no ser sor mi dialecto costa tan seguro de no ser Vallejo. No obstante, voy a intentar desJuable enredo, ino será que soy Borges? Qué va, no creo, aún no estoy tan ciego. Y si lo fuera, ¿cuál de los dos sería iQué locural Juro que no he estado fumando nada.

"Que cada quien hable por sí mismo, en nombre propio, y diga lo que tenga que decir"

Pues bien, el primer punto al que me voy a referir es quizá tan evidente como medular. La tradición ensayística que mencionamos a partir de José Cecilio del Valle procuró determinar, digámoslo así, el gen de lo latinoamericano. De alguna manera intentó tomar la palabra para hablar sobre la esencia de todos nosotros, para hablar por todos. Quiso ser la voz del subcontinente. En ese matarile han seguido un chorro de dizque estudiosos hasta la fecha. Vallejo, por su lado solo se refiere a sí mismo, dice yo por todas partes, a diestra y siniestra, como le fuera en ello la vida. En otras palabras, opone la subjetividad a la identidad colectiva, pues para él no se puede conocer nada fuera de lo que uno mismo ve con sus propios ojos. De aquí sus ataques contra los narradores omniscientes, entre ellos uno que ya mencionamos y que forma part de la discusión identitaria: Gabriel García Márquez, quien le dice:

Gabito: No te preocupés que vos estás por encima de toda crítica y honradez. Vos que todo lo sabés y lo ves y lo olés no sos cualquier hijo de vecino: sos un narrador omnisciente como el Todopoderoso, un verraco. $Y$ tan origina que cuanto hagás con materiales ajenos te resulta prop
(Vallejo, 2013, pp. 303-304).

Vallejo sustituye el "nosotros" por el "yo", al cual llamamos subjetividad y no identidad personal porque la identidad implica mismidad, propiedad, certeza de sí, y tanto él como nosotros estamos partidos, condenados más la posición quijotesca de inventarse un carácter. To be or not to be, ser o no ser latinoamericano. iser, To be or not to be, ser o no ser latinoamericano. jer la cosa

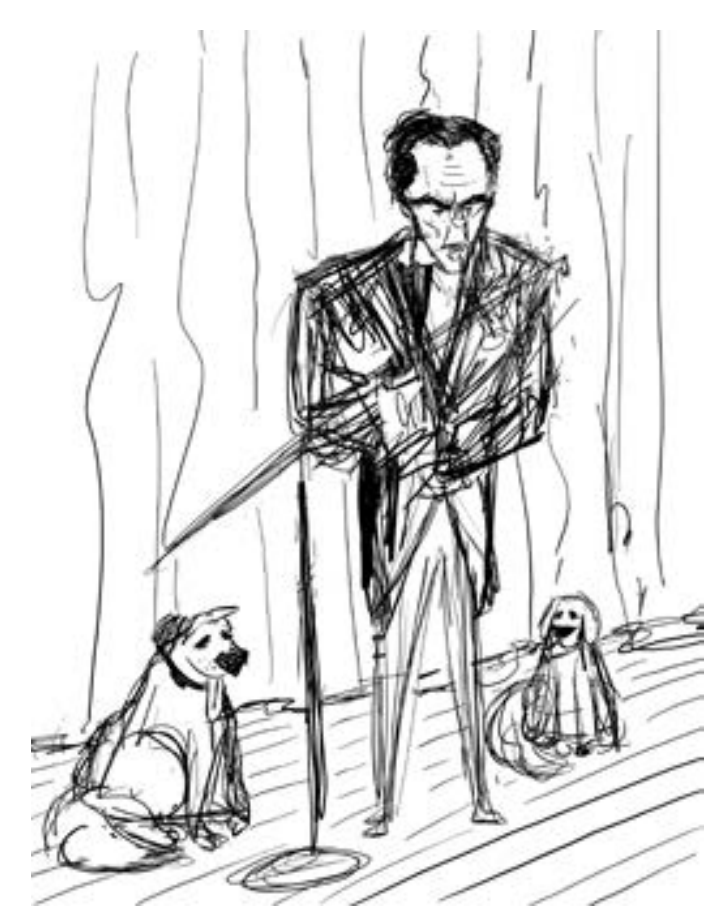

En uso de esa libertad espléndida

Sin título.

Aun así, el colombo-mexicano, como él se autodefine, no nos niega algunas palabras sobre Latinoamérica. El último reducto de la libertad, así la llama. Ante todo de la libertad de palabra, pues en ninguna otra parte ha podido afirmar con holgura que Dios no existe y que si existe es malo, que Cristo no existió tampoco y que el cristianismo es una empresa criminal. No lo pudo hacer en Europa, poco donde la gente le tiraba los audifonos de traduccion simultánea al tiempo que de los norteamericanos y mucho mos en los palses musuman Empero, no todo son halagos para el mal llamado Nuevo Mundo. De la misma ama y lo que conoce, algo que nosotros podemos extender al resto de Latinoamérica dado el caso de que nuestros países se parecen más de lo que quisieran. Para Vallejo esto es el Infierno: un desierto hacinado de degradados morales donde todo el mundo es diferente excepto cuando come, caga o se reproduce. De esta identidad orgánica es de donde nos viene tanta miseria. Sobre todo la De esta identidad orgánica es de donde nos viene tanta miseria. Sobre todo la hacemos todavía con los animales.

La otra miseria, la económica, viene de ahí también: de la mala costumbre de la también mal llamada democracia, el sistema perfecto para alcahuetear a los pillos saqueadores del Estado en concubinato con la Iglesia que, con la misma boca con que les mama la teta, Ilama a sus ovejas carnívoras a reproducirse. La Iglesia no sabe nada de nada, ni de identidad, ni de ética, ni de matemáticas, ni de sexo, porque una vez que aparecen las nuevas bocas no hay comida ni quién les dé de comer, a pesar de que todos reciban de Dios su diaria porción de aire, cuya purificación ya se le va haciendo difícil al Creador.

Una tercera miseria tiene lugar en el empobrecimiento lingüístico del español. Para el centenario de la muerte de Rufino José Cuervo, el segundo beato del ecrica: llustración digital

กิ̃: 2015 


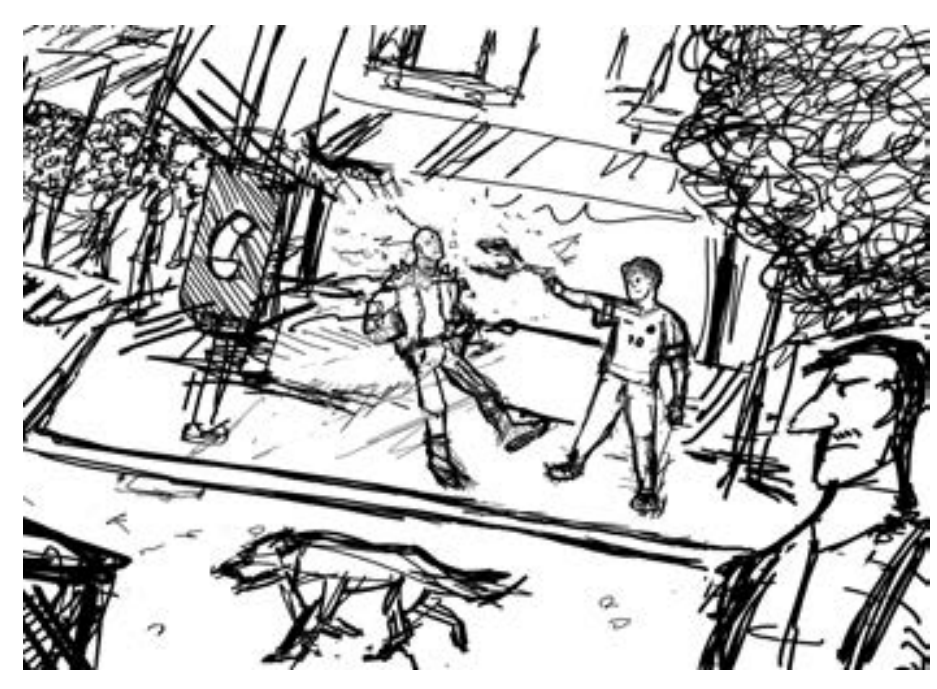

santoral que inició canonizando a Cervan tes, Vallejo lamenta la contaminación de vasto río de la lengua, ahora enturbiado con anglicismos aceptados parsimoniosa mente por la iglesia del idioma: la RAE. Asi el idioma sea, como todo rí, un objeto cambiante y escurridizo, dedicado a la pilleria, nada justifica que se lo empuerque con "un toper por ejemplo, o un CD, o un spray, un celular, un boligrafo, un que galicondon..." (Valejo, 2013, p. 139). dicho mos que se intente fijar, como inteligencia de los marrana 20 es que inteligencia de los marranos!, 20 es que en do diques? Cada quien es sus palabras y do diques? Cada quien es sus palabras, y asi se nos ensucia el alma, eso que nos concedió Las Casas. Que se ensucie Fernato, si de por sí es un trapo ajeno, una sotana de cura que nunca ha estado adentro sino de por si es un trapo ajeno, una sotana de cura que nunca ha estado adentro sino Año: 2015 va para donde van el libro y el mundo, que es para donde vamos nosotros: para la nada de donde vinimos. Ahí sí nos vamos a encontrar todos.

"Sin acabar de irme, sin saber quedarme, sin saber por qué"

Todavía hay más. En el discurso "A los muchachos de Colombia" aparece un detalle importante: el destino de los colombianos es irse de su país huyendo de la violencia y del subdesarollo. Rojas Mix (1991) aseveró que los inmigrantes ayudaron en gran medida a formar Latinoamerica, tanto que se constituyeron en viajar. Los latinoamericanos vivimos nostálgicamente, en el sentido más propio de la palabra: como Odiseo, anorando el regreso a una casa que nunca hemos tenido. ¿Cuántos se han ido? ¿Cuántos sueñan con irse? ¿Quién no tiene en familia a alguien que vive "afuera"? En mi familia, durante las fiestas del fin de año, siempre reservan un momento para agradecimientos y oracionel fin de cuales piden, sin excepción, por los que no están, para que estén bien y las los proteja. A todos se les empañan los ojos. iClaro que están bien, si ninguno los pros a nosotros, siempre viendo por las ventanas buscando el otro lado, afuera nos crece por dentro como un vacío silencioso.

Estas cosas pasan en Latinoamérica, pero no somos eso, no podemos ser eso. Vallajo asegura que todos estos problemas forman parte del lastre infame de la Conquista y la Colonia. España vino con su Iglesia y entre las dos perpetraron el Genocidio de América, maquillado todavía en nuestras escuelas con el eufemismo de encuentro de culturas. Los muertos de trescientos años de violaciones mismo de encuentro de culturas. Los muertos de trescientos años de violaciones mos mano de la nube, ya que aunque se habla del tema en Peroratas, se sintetiza mejor en una entrevista reciente, publicada en línea: Cuando estalló la independencia, al abrigo de la invasión napoleónica de la pe-
nínsula, los españoles se fueron con lo que pudieron y san se acabó el asunto, dejándonos en pago un espíritu burocrático de tinterillos públicos y la plaga del cristianismo. Así que al diablo con el cuento de la madre patria. España no es patria nuestra ni nunca ha sido (Vallejo, 2013, párr. 4).

"Y punto, basta, eso es todo, no digo más porque los muertos no hablamos"

En resumidas cuentas, no hay que buscarle cinco patas al gato: América Latina no tiene identidad. Si alguna vez tuvo una, se la cortaron a punta de espada y cruz. Esto es el Infierno, lo que sobra es calor, hambre y angustia. Aquil no hay nada que nos pueda decir, esta vaina no tiene nombre. Dirán que no, que la identidad es multiple deiversa, pero eso no es más que cristianismo: repetir, una vez más, el cuento absurdo de la trinidad. Ni dos nitres ni cuatro en uno: aqui no hay unidad de nada, ni politica, ni racial, ni espiritual, ni cultural. Enhorabuena, porque no la nacesitamos. Lo que necesita America Latina es sacar del poder a los ladrones y a los corruptos. Necesita que la gente deje de parir, que haya

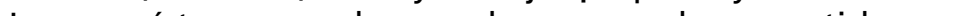

Lo que si tenems, de culacan, para quien el " Con hus huellas nos inventamos ficciones. Que lo diga Lacan, par ima nos muestran un espejo. El yo narcisista, para ser exactos. Porque nuestra etro nos ve como somos, y estamos todos an el ladrillo de cristal En to do caso, sigos ve como somos, y estamos todos en in lodillo de cristal. En todo caso, sigamos el consejo de Vallejo y tiremos a Lacan al basurero. No hace falta donde leemos esto y somos esto que no somos. dad tampos Ambos son edificios de polabras socavados por el río del tientiSomos nada o casi nada: somos metáforas, de nosotros mismos y de los dempo.

\section{Bibliografía}

Barthes, Roland. (2004). Roland Barthes por Roland Barthes. España: Paidós. Barthes, Roland. (2009). La cámara lúcida. España: Paidós.

Bierce, Ambrose. (2013). The Devil's Dictionary. Nueva York: Dover.

Borges, Jorge Luis. (1975). El Hacedor. Madrid: Alianza.

Carpentier, Alejo. (1984). Ensayos. La Habana: Editorial Letras Cubanas.

Chaves, Luis. (2010). 300 páginas. Estados Unidos: Ediciones Lanzallamas.

Cortázar, Julio. (2001). Historias de cronopios y de famas. España: Punto de Lectura. Cortez, Beatriz. (2010). Estética del cinismo. Guatemala: F\&G Editores.

Cruz de la, Sor Juana Inés. (2001). "Respuesta de la poetisa a la muy ilustre Sor Filotea de la Cruz". En: Obras Completas, tomo IV. México D. F.: Fondo de Cultura Económica. 
Fernández, Roberto. (1979). Calibán y otros ensayos. La Habana: Editorial Arte y Literatura.

Fernández, Roberto. (2004). Todo Calibán. San José: Editorial Universidad de Costa Rica.

Fuentes, Carlos. (2002). En esto creo. México D.F.: Seix Barral.

Fuentes, Carlos. (2011). La gran novela latinoamericana. Madrid: Santillana.

García, Gabriel. (2010). Yo no vengo a decir un discurso. México D.F.: Mondadori.

Henríquez, Pedro. (1998). Ensayos. Madrid: ALLCA XX.

Lacan, Jacques. (2009). Escritos 1 y 2. México: Siglo XXI.

Lacan, Jacques. (2010). Los cuatro conceptos fundamentales del psicoanálisis. Buenos Aires: Paidós.

Lavolé, L. \& Pragier, I. (Productores). Safaa Fathy. (Director). (1999). D’ailleurs, Derrida. (Documental). Francia: Gloria Films.

Martí, José. (1991). Nuestra América. La Habana: Instituto Cubano del Libro.

Paz, Octavio. (2000). El laberinto de la soledad. Madrid: Ediciones Cátedra.

Reyes, Alfonso. (2004). Visión de Anáhuac y otros ensayos. México D. F.: Fondo de Cultura Económica.

Rodó, José Enrique. (1985). Ariel/Motivos de Proteo. Caracas: Fundación Biblioteca Ayacucho.

Rojas Mix, Miguel. (1991). Los cien nombres de América: Eso que descubrió Colón. San José: Editorial Universidad de Costa Rica.

Vallejo, Fernando. (2012). La virgen de los sicarios. México: Punto de Lectura.

Vallejo, Fernando. (2013). Peroratas. México: Alfaguara.

Vallejo, Fernando. (2013). “Fernando Vallejo: 'La RAE publicó 22 ediciones de un diccionario acientífico, monárquico y clerical'". Recuperado de: http:// www.revistaenie.clarin.com/literatura/Fernando-Vallejo-Peroratas-idiomaespanol_0_981502201.html.

Vasconcelos, José. (1999). La raza cósmica. Heredia: EFUNA.

Vonnegut, Kurt. (2011). Breakfast of Champions. En: Vonnegut: Novels \& Stories 1963-1973. Estados Unidos: The Library of America.

Ziering, Amy (Productora). Ziering, Amy \& Dick, Kirby (Directores). (2002). Derrida. (Documental). Estados Unidos: Zeitgeist Films. 